This item was submitted to Loughborough's Research Repository by the author.

Items in Figshare are protected by copyright, with all rights reserved, unless otherwise indicated.

\title{
Comparative study of the structural and optical properties of epitaxial CuFeO2 and CuFe1 - xGaxO2 delafossite thin films grown by pulsed laser deposition methods
}

\section{PLEASE CITE THE PUBLISHED VERSION}

http://dx.doi.org/10.1016/j.tsf.2017.02.005

\section{PUBLISHER}

(C) Elsevier

\section{VERSION}

AM (Accepted Manuscript)

\section{PUBLISHER STATEMENT}

This work is made available according to the conditions of the Creative Commons Attribution-NonCommercialNoDerivatives 4.0 International (CC BY-NC-ND 4.0) licence. Full details of this licence are available at: https://creativecommons.org/licenses/by-nc-nd/4.0/

\section{LICENCE}

CC BY-NC-ND 4.0

\section{REPOSITORY RECORD}

Wheatley, R.A., S. Rojas, C. Oppolzer, Toyanath Joshi, Pavel Borisov, David Lederman, and A.L. Cabrera. 2019. "Comparative Study of the Structural and Optical Properties of Epitaxial Cufeo2 and Cufe1 - Xgaxo2 Delafossite Thin Films Grown by Pulsed Laser Deposition Methods". figshare.

https://hdl.handle.net/2134/25819. 


\title{
Comparative study of the structural and optical properties of epitaxial $\mathrm{CuFeO}_{2}$ and $\mathrm{CuFe}_{1-\mathrm{x}} \mathrm{Ga}_{\mathrm{x}} \mathrm{O}_{2}$ delafossite thin films grown by pulsed laser deposition methods
}

\author{
R. A. Wheatley ${ }^{1}$, S. Rojas ${ }^{1}$, C. Oppolzer ${ }^{1 t}$, T. Joshi $^{2}$, P. Borisov ${ }^{2}$, D. Lederman ${ }^{2,3}$ and A.L. Cabrera ${ }^{1}$ \\ ${ }^{1}$ Instituto de Física, Pontificia Universidad Católica de Chile, Av. Vicuña Mackenna 4860, Macul, \\ Santiago, Chile \\ ${ }^{2}$ Department of Physics and Astronomy, West Virginia University, Morgantown, West Virginia 26506- \\ 6315 , USA \\ ${ }^{3}$ Department of Physics, University of California, Santa Cruz, CA 95064, USA
}

\begin{abstract}
:
Three samples of epitaxial delafossite $\mathrm{CuFeO}_{2}$ and $\mathrm{CuFe}_{1-\mathrm{x}} \mathrm{Ga}_{\mathrm{x}} \mathrm{O}_{2}$ films were grown using Pulsed Laser Deposition techniques in high vacuum. The sample thicknesses were estimated to be $21 \mathrm{~nm}, 75 \mathrm{~nm}$ for the $\mathrm{CuFeO}_{2}$ films and $\sim 37 \mathrm{~nm}$ for the composite sample containing gallium. The estimated gallium fraction of substituted ferric atoms was $\mathrm{x}=0.25$ for the composite sample. We present the study of the fundamental band gap(s) for each sample via observation of their respective optical absorption properties in the NIR-VIS region using transmittance and diffuse reflection spectroscopy. Predominant absorption edges measured at $1.1 \mathrm{eV}$ and $2.1 \mathrm{eV}$ from transmittance spectra were observed for the $\mathrm{CuFeO}_{2}$ samples. The sample of $\mathrm{CuFe}_{1-\mathrm{x}} \mathrm{Ga}_{\mathrm{x}} \mathrm{O}_{2}$ showed a measurable shift to $1.5 \mathrm{eV}$ of the lower bandgap and a strong absorption edge located at $2.3 \mathrm{eV}$ attributed to direct band to band transitions. This study also found evidence of changes between apparent absorption edges between transmittance and diffuse reflectance spectroscopies of each sample and it may be resultant from absorption channels via surface states.
\end{abstract}

${ }^{\dagger}$ permanent address: Technische Universitat Wien, Austria 


\section{Introduction}

There is an increasing worldwide concern about developing new sources of energy which are not reliant directly on the combustion of fossil fuels [1-4]. This is due, in part, to the finite nature of oil reserves and its potential affect upon future energy markets. Moreover, there are the environmental problems associated with pollution, which are more often concentrated in areas of dense population; both problems arise in addition to concerns about increasing global atmospheric carbon dioxide concentrations (amongst other greenhouse gases). Attractive alternatives include the production of hydrogen from water dissociation and carbon dioxide reformation into methane, both of which also have the potential to use solar energy in conjunction with photo-catalytic molecular decomposition processes.

Water dissociation by electrochemical photolysis was pioneered by Fujishima and Honda in 1972 [5] with experiments using $\mathrm{TiO}_{2}$ photoelectrodes. Other widely reported electrode materials used for overall watersplitting are $\mathrm{WO}_{3}, \mathrm{CdS}$, amongst others including many varieties of multi-component compounds [6-7] which are broadly reviewed in [8]. However, research continues for a chemically stable material with a band gap greater than the water splitting potential of $1.23 \mathrm{eV}$. Such materials should also display strong band to band absorption characteristics corresponding to peak solar irradiance, it is predicted that such materials would enhance the efficiency of the photo-catalytic molecular decomposition [6-9].

A promising class of materials for these applications is the delafossite oxide. These compounds are characterized by the general chemical formula $\mathrm{ABO}_{2}$, where $\mathrm{A}$ is a monovalent cation and $\mathrm{B}$ is a trivalent metal from Al to La [10]. This oxide family also displays multi-band-gap semiconductor behavior, with energy gaps ranging between $1.1 \mathrm{eV}$ and $3.6 \mathrm{eV}$, and shows band to band absorption characteristics in response to illumination by UV, visible and near infrared light. As with more common 
semiconductor materials, the band gap(s) can be adjusted by changing the composition of the oxide. An additional advantage of these complex oxides is the relative abundance of their main composite materials in the form of $\mathrm{Cu}, \mathrm{Fe}, \mathrm{Al}, \mathrm{Ga}$, etc.

The $\mathrm{CuFeO}_{2}$ delafossite oxide is known to be a p-type semiconductor [10], however reports of the fundamental energy gap vary widely. There are reports of multiple dominant absorption edges forming step like patterns in the optical spectra of delafossite $\mathrm{CuFeO}_{2}$, which are thought to emerge from the super-positioning of $\mathrm{CuO}_{2}$ and $\mathrm{Fe}_{2} \mathrm{O}_{3}$ absorbance properties within the composite delafossite $\mathrm{CuFeO}_{2}$ [11]. Additionally, the breaking of dipole forbidden transition mechanisms is thought to emerge from Fe-3d states positioned within the forbidden regions of the crystalline structure [12]. Empirical testing has revealed strong absorption edges determined in the near infrared region between $1.1 \mathrm{eV}$ and $1.3 \mathrm{eV}$ $[13,15]$, the mid-visible region between $1.6 \mathrm{eV}$ and $2.0 \mathrm{eV}$ [14-15], with higher energy band to band optical transitions also apparent for the blue-ultraviolet region between 3.0 and $3.4 \mathrm{eV}$ [15]. There are also reports of direct absorption edges located at $1.6 \mathrm{eV}$, with further absorption edges in the visible region at $2.0 \mathrm{eV}-2.4 \mathrm{eV}$ with variable high energy absorption edges approaching the $\mathrm{UV}$ region typically between 3.1-3.8 eV, showing both direct and indirect characteristics from Tauc-gap analysis [16].

In terms of four-component delafossite compounds, there are reports which describe the growth and characterization of substitutional formations, for example $\mathrm{CuFe}_{1-\mathrm{x}} \mathrm{Cr}_{\mathrm{x}} \mathrm{O}_{2}$ [17], $\mathrm{CuCr}_{1-\mathrm{x}} \mathrm{Ni}_{\mathrm{x}} \mathrm{O}_{2}$ [18] and $\mathrm{CuCr}_{1-\mathrm{x}} \mathrm{Mg}_{\mathrm{x}} \mathrm{O}_{2}$ [19]. More specific to this work, the chemical synthesis and characterization of $\mathrm{CuGa}_{1-\mathrm{x}}$ $\mathrm{Fe}_{\mathrm{x}} \mathrm{O}_{2}$ delafossite has been reported previously [20], where it was shown that the substitution of Ga for Fe within $\mathrm{CuGaO}_{2}$ compounds led to a strong absorption edge measured at $1.5 \mathrm{eV}$ which was not observed in the host lattice material $\mathrm{CuGaO}_{2}$, This strong absorption was attributed to the activation of forbidden optical channels by crystal symmetry breaking within the host material rather than solely due to the hybridization of band-structures described by the empirical Vegard's law. 
In terms of photo-catalytic experiments, there are recent reports of successful photocatalytic watersplitting using $\mathrm{CuGaO}_{2}$ electrodes, for which the $\mathrm{CuGaO}_{2}$ material has shown favorable attributes in terms of its ability to catalyze overall water-splitting of adsorbed $\mathrm{H}_{2} \mathrm{O}$, meaning that its band edges are likely to be situated at suitable energies for satisfying the conditions for $\mathrm{H}_{2} \mathrm{O}$ redox potential. However, Lee et al [21] also describe reduced photocatalytic activity below UV wavelengths $(\mathrm{hv}<3.2 \mathrm{eV})$, despite $\mathrm{CuGaO}_{2}$ having also shown weaker absorption edges around $2.7 \mathrm{eV}$ in separate studies [21]. In the case of pure $\mathrm{CuFeO}_{2}$, despite its lower band gap and higher absorbance through the visible spectrum, it is not thought to be suitable in terms of its band edge potentials for full reduction-oxidation of $\mathrm{H}_{2} \mathrm{O}$ [20]. From this standpoint, and with respect to the development of both $\mathrm{CuFeO}_{2}$ and $\mathrm{CuGaO}_{2}$ delafossite materials for the purpose of photo-catalysis, B-site alloying presents a possible means of extending the absorption properties of a candidate delafossite electrode material into the visible spectrum, and provides a potential to enhance photo-catalytic efficiency of the material when operating within the visible spectrum close to peak solar irradiance at sea-level.

In this work, a similar approach to [20] is undertaken but with substitution of $\mathrm{Ga}$ for Fe within the $\mathrm{CuFeO}_{2}$. We have previously published an X-ray photoelectron spectroscopy study of a $\mathrm{CuFe}_{1-\mathrm{x}} \mathrm{Ga}_{\mathrm{x}} \mathrm{O}_{2}$ composite thin film and reported its chemisorption properties related to $\mathrm{CO}_{2}$ gas exposure [22]. In this article, we extend our previous work by concentrating the analysis of optical properties of a fourcomponent $\sim 37 \mathrm{~nm}$ thick $\mathrm{CuFe}_{1-\mathrm{x}} \mathrm{Ga}_{\mathrm{x}} \mathrm{O}_{2}$ epitaxial thin film material grown by pulsed laser deposition (PLD). The optical characteristics of the sample are shown in direct comparison to those obtained from two other samples of epitaxial $\mathrm{CuFeO}_{2}$ thin films, of thicknesses $21 \mathrm{~nm}$ and $75 \mathrm{~nm}$, also grown by PLD, using the same apparatus. The high quality epitaxial nature of the thin film samples is confirmed by XRD and Raman spectroscopies. Observations are made of comparative absorption properties using normalized transmittance and diffuse reflectance spectra. The energy gaps obtained were analyzed firstly for the variation in observed absorption edge with respect to the substitution of Ga for Fe; 
secondly, for the variation in observed absorption edges with respect to the possible dependence on optical path length and surface states.

\section{Experimental Methods}

\section{Sample Growth/Preparation Description}

$\mathrm{CuFeO}_{2}$ (001) films were deposited onto $\mathrm{Al}_{2} \mathrm{O}_{3}$ (001) substrates from a stoichiometric polycrystalline $\mathrm{CuFeO}_{2}$ target using pulsed laser deposition. Details of the experimental setup and procedure have been described elsewhere [13]. For the multilayer structure, a buffer layer of 9 monolayers $(3 \mathrm{~nm})$ of $\mathrm{CuFeO}_{2}$ was grown on top of the sapphire substrate. Then one monolayer $(0.3 \mathrm{~nm})$ of $\mathrm{CuGaO}_{2}$ was deposited on top, followed by three monolayers $(1.3 \mathrm{~nm})$ of $\mathrm{CuFeO}_{2}$. This $\mathrm{CuGaO}_{2} / \mathrm{CuFeO}_{2}$ was repeated 21 times $(37 \mathrm{~nm})$. The surface was terminated by $\mathrm{CuFeO}_{2}$. The film was grown in a vacuum system at $600{ }^{\circ} \mathrm{C}$ under an $\mathrm{O}_{2}$ partial pressure of $1.33 \times 10^{-2} \mathrm{~Pa}$.

\section{XRD Description}

A four-axis Rigaku X-ray diffraction (XRD) system with a $\mathrm{Cu} \mathrm{K} \alpha$ rotating anode and Huber goniometers was used for structural characterization of the deposited films. $\mathrm{CuFeO}_{2}$ and $\mathrm{CuFe}_{2} \mathrm{O}_{4}$ phases were identified using powder diffraction files no. 01-075-2146 and no. 00-025-0283 respectively.

\section{Raman spectroscopy}

Raman spectra were obtained using a LabRam010 system from Instruments, S.A. (Horiba), featuring a $5.5 \mathrm{~mW}$ He-Ne laser (632.8 $\mathrm{nm}$ wavelength). This instrument used an Olympus confocal optical microscope with a light spectrometer in a back-scattering geometry, the incident beam was linearly polarized and spectral detection was unpolarized. The spectra were taken at room temperature using a 100X objective ( $\sim 10 \mu \mathrm{m}$ spot size) with an energy resolution of approximately $1 \mathrm{~cm}^{-1}$.

\section{Optical Properties}

\section{A visible/NIR transmittance and reflectance spectroscopy system was set up to measure the}


optical response of the samples. A schematic of the apparatus is shown in Figure 1. A $100 \mathrm{~W}$ tungsten halogen lamp provides the broadband light source. PD-2 is the photodetector used to collect transmitted light, PD-1 is the photodetector used to collect reflected light (angle of reflectance $\theta<10^{\circ}$ ); transmittance is recorded at normal incidence $\left(\theta=0^{\circ}\right)$. The beam is chopped $(730 \mathrm{~Hz})$ before entering the monochromator, and the signals are measured using lock-in amplifiers. The monochromator (Triax 180, Jobin Yvon-Horiba) is equipped with a $1200 \mathrm{~g} / \mathrm{mm}$ blazed ruled grating, and set up to provide a $1 \mathrm{~nm}$ FWHM. All data is normalized to the bulb spectrum.

\section{Results; XRD}

Figure 2 shows results of XRD diffraction spectra for both $\mathrm{CuFeO}_{2}$ samples. The c-axis peaks corresponding to (003), (006), (009) and (0012) oriented planes show that high quality epitaxial $\mathrm{CuFeO}_{2}$ was achieved during growth. Although there was some evidence for the formation of $\mathrm{CuFe}_{2} \mathrm{O}_{4}$ spinel material within the thicker $\mathrm{CuFeO}_{2}$ sample, where small peaks corresponding to known (222) and (333) oriented planes are visible. XRD pattern obtained for the $\mathrm{CuFe}_{1-\mathrm{x}} \mathrm{Ga}_{\mathrm{x}} \mathrm{O}_{2}$ sample has been reported previously [22], with some evidence of spinel impurities were also recorded (as discussed above) on that pattern. The Ga content was estimated at $25 \%$ taking into account the onset of strain resulting from the increased lattice mismatch between $\mathrm{CuGaO}_{2}$ and the $\mathrm{Al}_{2} \mathrm{O}_{3}$ substrate.

\section{Results; Raman Spectroscopy}

Figure 3 shows the spectral region corresponding to expected delafossite peak Raman shift(s); these results show good agreement with expected Raman shift positions as reported by [23]. The $\mathrm{CuFeO}_{2}$ samples showed a typical delafossite spectrum with three main peaks at 350,511 and $689 \mathrm{~cm}^{-1}$. The peak located at $350 \mathrm{~cm}^{-1}$ was attributed to the $\mathrm{E}_{\mathrm{g}}$ vibrational mode along the c-axis of the octahedral structure, the peak at $689 \mathrm{~cm}^{-1}$ was attributed to the $\mathrm{A} 1 \mathrm{~g}$ vibrational mode along a plane perpendicular 
to the c-axis; the peak at $511 \mathrm{~cm}^{-1}$ was attributed to non-zero wave vector phonons typical of crystalline defects, as described in [23]. For the $\mathrm{CuFe}_{0.75} \mathrm{Ga}_{0.25} \mathrm{O}_{2}$, one can observe the same peak structure, however displaced by $16 \mathrm{~cm}^{-1}$ to a higher Raman shift. For pure $\mathrm{CuGaO}_{2}$, expected Raman peaks are located at the higher values of 368 and $729 \mathrm{~cm}^{-1}$ [24], therefore the Ga content must explain the shifting observed in our results. Moreover, the apparent group shift of the delafossite peaks, as opposed to line broadening or splitting of modes, was an indication of homogeneous hybridization of the lattice structure with respect to the inclusion of $\mathrm{Ga}$ as a fourth component of the material; at least in terms of the Raman channels generated by the overall crystalline thin film. The peaks in figure 2 labeled with an asterisk (*), located at 415,640 and $750 \mathrm{~cm}^{-1}$, correspond to those typically found for the $\mathrm{Al}_{2} \mathrm{O}_{3}$ substrate material [22].

Figure 3 also shows a broad peak emerging at $500-520 \mathrm{~cm}^{-1}$. This peak is attributed to defect channels thought to emanate from combined $\mathrm{Cu}$ vacancies, $\mathrm{Fe}^{3+}$ substitution into $\mathrm{Cu}$ sites, and oxygen interstitial defects [25]. An increase in spectral peak magnitude was observed between the $\mathrm{CuFeO}_{2} \mathrm{samples}$, occurring due to the increase in film thickness and volume. By observing the blue line corresponding to the $\mathrm{CuFe}_{0.75} \mathrm{Ga}_{0.25} \mathrm{O}_{2}$ sample, one can view both a further increase in intensity and a relative shift in accordance with the main delafossite peaks; again this effect must be attributed to the Ga substitution. The peak found at $511 \mathrm{~cm}^{-1}$ in $\mathrm{CuFeO}_{2}$, and found to be shifted to $527 \mathrm{~cm}^{-1}$ for the $\mathrm{CuFe}_{0.75} \mathrm{Ga}_{0.25} \mathrm{O}_{2}$ sample, emerges in principle due to the relaxation of selection rules, via defect states in the $\mathrm{CuFeO}_{2}$ samples, and enhanced in the $\mathrm{CuFe}_{0.75} \mathrm{Ga}_{0.25} \mathrm{O}_{2}$ sample. This result may have occurred due to the combination of intrinsic defect states and by crystal symmetry breaking by the inclusion/substitution of $\mathrm{Ga}$ in the octahedral Fe-O sites.

\section{Results- Optical Spectroscopy}

Transmittance spectra were recorded for all samples. A comparative view of transmittance spectra for all samples is shown in Figure 4a. For the sake of shorthand terminology, samples A and B refer to the 
$21 \mathrm{~nm}$ and $75 \mathrm{~nm} \mathrm{CuFeO}_{2}$ thin films, respectively, while sample $\mathrm{C}$ refers to the composite $\sim 37 \mathrm{~nm}$ $\mathrm{CuFe}_{1-\mathrm{x}} \mathrm{Ga}_{\mathrm{x}} \mathrm{O}_{2}$ thin film. Diffuse reflectance was obtained for sample A and $\mathrm{C}$ and the respective spectra are shown in Figure 4b. Diffuse reflectance could not be measured for sample B due to the larger surface roughness as a result of growing a thicker film.

Firstly, the spectra of sample C contained clearly observable step-like absorption features between photon energies $1.6 \mathrm{eV}-3.5 \mathrm{eV}$ not present in the samples of pure $\mathrm{CuFeO}_{2}$, clearly demonstrating the modification of the film absorbance properties in connection to the substitution of Fe for Ga. Samples $\mathrm{A}$ and B showed relatively stronger absorption in the NIR-(Red)/VIS regions (in the range $1.0 \mathrm{eV}<\mathrm{h} v$ $<1.5 \mathrm{eV}$ ) when compared with sample $\mathrm{C}$. Between the $\mathrm{CuFeO}_{2}$ samples the highest absorption in the Vis region was found for sample B $(75 \mathrm{~nm})$, this was consistent with the variation in thickness and optical path of absorption. The expected step-like formations of absorption edges were clearly visible from the spectra of sample $\mathrm{C}$ (containing $\mathrm{Ga}$ ). The multiple step feature displayed by sample $\mathrm{C}$, at hv > $1.5 \mathrm{eV}$, culminated in a decrease of the fractional transmittance at higher energies $(\mathrm{h} v>1.8 \mathrm{eV})$ relative to the pure $\mathrm{CuFeO}_{2}$ samples. The variation seen in Figure 4a was attributed to the bulk film absorbance properties of the samples, as the comparative reflectance between samples, as shown in Figure 4b, did not display apparent step-like patterns.

Tauc-gap analysis was performed on each spectrum in order to further relate spectral absorption edges with estimations of direct and indirect band to band transition energies and the band gap from which they emerged. The transmittance spectra results were then treated in order to determine the band gap energy $\left(E_{g}\right)$ of each sample using Tauc`s expression [26, 27]:

$$
\alpha h v=b\left(h v-E_{g}\right)^{n} \quad \text { Equation (1) }
$$

In Ecuation (1), $h$ is the plank constant, $v$ is the frequency of the incident light, $\alpha$ is the absorption coefficient, $b$ is a proportion constant and $E_{g}$ is the band gap energy defined as the difference between the lowest energy level in conduction band and the highest energy level in valence band. When 
linearity was identified within the Tauc plot, extrapolation to the $\mathrm{x}$ axis revealed possible optical band gap energies for the sample. The plotting was repeated, once using power $n=1 / 2$ so as to identify direct gap behavior, and secondly using power $n=2$ to identify behavior characteristic of indirect energy gaps within the samples.

Secondly, diffuse reflectance spectra were analyzed. The surface optical absorbance characteristics were estimated using the Kubelka-Munk function

$$
\mathrm{F}(\mathrm{R})=(1-\mathrm{R})^{2} / 2 \mathrm{R} \quad \text { Equation }(2)
$$

which was then used to construct a Tauc-plot of $\mathrm{F}(\mathrm{R}) \mathrm{h} v$ vs $\mathrm{h} v$, as demonstrated in $[28,29]$. In this regime $F(R)$ is proportional to the absorption coefficient, such that the function $(F(R) h v)^{2}$ relates to direct band gaps, and $(\mathrm{F}(\mathrm{R}) \mathrm{hv})^{1 / 2}$ relates to indirect band gaps, for the interest of the reader these methods are reviewed in [30]. Figures 5 (a) and (b) show the Tauc-plots obtained for direct transition $\left(\sim \alpha^{2}\right)$ from the transmittance spectra for samples A and B respectively. Figure 5 (c) shows the Taucplot from transmittance spectra of sample C.

A comparative view of the relative optical densities of the samples calculated is displayed in Fig. 6. Relative optical densities are calculated using OD $=0.404(\alpha)$ [34], where $(\alpha)$ is the absorption coefficient and (l) is the estimated optical path length (the film thickness).

Figure 7a shows the Tauc-plot for the K-M function of reflectance in the direct gap regime for sample A (21 nm CuFeO 2 thin film) and Figure $7 \mathrm{~b}$ shows the same for sample $\mathrm{C}\left(\sim 37 \mathrm{~nm} \mathrm{CuFe} \mathrm{e}_{1-\mathrm{x}} \mathrm{Ga}_{\mathrm{x}} \mathrm{O}_{2}\right.$ thin film).

The results for recorded energy gaps (pertaining to measurable absorption edges), for all samples, from 
both the transmittance and reflectance measurements are summarized in Table 1.

\begin{tabular}{|l|l|l|}
\hline Sample & $\begin{array}{l}\text { Transmittance Tauc-gap(s) } \\
\text { (direct) }\end{array}$ & $\begin{array}{l}\text { Reflectance Tauc-gap(s) } \\
\text { (direct). }\end{array}$ \\
\hline A) $\mathrm{CuFeO}_{2} 21 \mathrm{~nm}$ & $1.3 \mathrm{eV}$ and $2.2 \mathrm{eV}$ & $1.4 \mathrm{eV}$ \\
\hline B) $\mathrm{CuFeO}_{2} 75 \mathrm{~nm}$ & $1.2 \mathrm{eV}$ and $2.2 \mathrm{eV}$ & \\
\hline C) $\mathrm{CuFe}_{1-\mathrm{x}} \mathrm{Ga}_{\mathrm{x}} \mathrm{O}_{2} \sim 37 \mathrm{~nm}$ & $1.5 \mathrm{eV}$ and $2.3 \mathrm{eV}$ & $1.3 \mathrm{eV}$ \\
\hline
\end{tabular}

Table 1 displays a summary of all measurable absorption edges and corresponding estimated Taucgaps.

\section{$\mathrm{CuFeO}_{2}$ absorption characteristics}

The Tauc plot obtained for sample A is shown in Figure 5a. From transmittance, the first fundamental Tauc-gap was measured at $1.3 \mathrm{eV}$ for the range between $1.0-2.0 \mathrm{eV}$, forming fair agreement with those reported in $[13,14 \& 15]$. At higher energies, a secondary Tauc-gap was observed at $2.2 \mathrm{eV}$ and possibly a third absorption edge pertaining to $\sim 3 \mathrm{eV}$. Again, agreement may be established with $[14,15]$ and the expected direct energy gaps cited in Refs. [11] and [31]. Inspection of the Tauc-plot for indirect transitions (not shown) revealed a strong singular absorption edge initiated at $1.0 \mathrm{eV}$ which was again in agreement with [13-15].

The Tauc-plot from transmittance for sample B (as shown in Figure 5b) indicates similar Tauc-gaps observed at $1.2 \mathrm{eV}$ within the $1.0-2.0 \mathrm{eV}$ range and $2.2 \mathrm{eV}$ for the $\mathrm{h} v>2.0 \mathrm{eV}$ range; forming agreement with the same references as for sample A. The Tauc plot of $(\alpha h v)^{\mathbf{1 / 2}}$ for sample B (not shown), produced a strong absorption edge around $1.0 \mathrm{eV}$.

The plot of the $\mathrm{K}-\mathrm{M}$ function of the reflectance spectra of sample A for the direct allowed transitions is displayed in Figure 7(a). Sample A showed a single absorption edge across the 1.0-3.0 eV range found at $1.4 \mathrm{eV}$. However, the band gap around $2 \mathrm{eV}$ observed from transmittance for both samples (A and B) was not observed by diffused reflectance in sample A. 
To discuss the results from both transmittance and reflectance reference is given to the theoretical work of Haycock et al [32]. For the $\mathrm{CuFeO}_{2}$ thin films, we have measured fundamental absorption edges in the region of 1.0-1.3 eV, these results can be compared and attributed to the expected 1.2-1.4 eV indirect $\mathrm{L}-\Gamma$ transitions forecasted in [32], with an expected Urbach tail formed from sub-gap indirect d-d state transitions. Both $\mathrm{CuFeO}_{2}$ samples displayed the activation of a direct transition in the 2.0-2.2 $\mathrm{eV}$ region, this absorption edge can be attributed to the activation of direct L-point transitions and direct $\Gamma$-point transitions calculated to be at $1.6 \mathrm{eV}$ and $2.4 \mathrm{eV}$ respectively [32]. It is possible that the absorption observed in this spectral region takes place via a super-positioning of direct transitions over both symmetry points. The measured band gaps from reflectance (Fig.7) show a main dependence on an absorption edge observed at $1.4 \mathrm{eV}$ corresponding to direct transitions. There are two possible ways of viewing this discrepancy between reflectance and transmittance data: Firstly, the absence of the absorption edge at $2.1 \mathrm{eV}$ could indicate that a relatively large optical path length is required in order for the direct $\mathrm{L}$ and $\Gamma$-point transitions to have a strong effect on the spectra. Secondly, because the lower band gap at 1.0-1.3 eV is expected to emerge from indirect transitions and the spectra shows a strong direct absorption edge in this region, the reflectance spectra may represent direct $\mathrm{L}$ and $\Gamma$-point transitions assisted by intra-gap states emerging from the discontinuity of the crystalline structure at the surface. In either case, these results suggest that relatively large optical path lengths are required to observe the absorption edge related to the direct fundamental gap within these samples.

Each spectrum obtained also indicates the activation of a possible higher absorption edge located in the range $h v>3.1 \mathrm{eV}$, these effects are particularly prominent in the reflectance spectra. Although such high band-gaps have been reported before $[14,15]$, these absorption edges are likely to be emanating from valence band to second conduction band transitions; or to absorption via channels located higher up within the conduction bands which are known to possess relatively high optical cross-sections. These higher energy absorption channels are thought to form an apparent optical edge - this 
explanation is explored in detail by Nie et al [33] and Huda et al [10].

\section{Substitution of Ga for $\mathbf{F e}\left(\mathrm{CuFe}_{1-\mathrm{x}} \mathrm{Ga}_{\mathrm{x}} \mathrm{O}_{2}\right)$}

Tauc-plots of transmittance and reflectance for sample $\mathrm{C}\left(\mathrm{CuFe}_{1-\mathrm{x}} \mathrm{Ga}_{\mathrm{x}} \mathrm{O}_{2}\right)$ are displayed in Figure $5 \mathrm{c}$ and $7 b$ respectively. For this sample, as expected due to the Ga substitution, the Tauc-gap characteristics were different from those of the pure $\mathrm{CuFeO}_{2}$ samples. First, the primary gap - located in the NIR region for $\mathrm{CuFeO}_{2}$ - was found to be close to $1.5 \mathrm{eV}$ for direct transitions showing an apparent upward shift in energy from the $1.3 \mathrm{eV}$ recorded for the pure $\mathrm{CuFeO}_{2}$ samples and may represent a change in optical gap brought about by the hybridization of $\mathrm{CuFeO}_{2}$ with $\mathrm{CuGaO}_{2}$. Further up the energy range, a strong absorption edge emerged corresponding to a Tauc-gap of approximately $2.3 \mathrm{eV}$. Moreover, the gradient of this absorption edge was found to have increased compared to the absorption edges at 2.2 $\mathrm{eV}$ for the pure $\mathrm{CuFeO}_{2}$ samples. In the indirect regime, the transmittance spectra displayed a step-like formation with three linear regions which correspond to Tauc-gaps ranging between 1.1 and $1.3 \mathrm{eV}$. The K-M function of the reflectance spectra of sample $\mathrm{C}$ is shown in figure $7 \mathrm{~b}$. The $\mathrm{K}-\mathrm{M}$ function for direct transitions was found to be largely similar to those gained for the $\mathrm{CuFeO}_{2}$ samples, with single absorption edge corresponding to a Tauc-gap of approximately $1.2 \mathrm{eV}-$ shifted downwards by $0.2 \mathrm{eV}$. As with the $\mathrm{CuFeO}_{2}$ samples, the absorption edge located in the $\mathrm{hv}>2.0 \mathrm{eV}$ range could not be observed.

The fundamental direct Tauc-gap measured at $1.5 \mathrm{eV}$ from transmittance is comparable to the absorption edge reported by Lekse et al [20] for $\mathrm{CuFe}_{1-\mathrm{x}} \mathrm{Ga}_{\mathrm{x}} \mathrm{O}_{2}$ with $\mathrm{x}=0.85$ who describe the position of this absorption edge as being independent of fractional Fe content. As with the studies of Lekse et al [20], an expected outcome of B-site alloying of $\mathrm{Ga}$ and $\mathrm{Fe}$ is the breaking of delafossite crystal symmetry, which is expected to modify selection rules leading to the increased availability of transition 
states. Moreover, Huda et al [10] also have described changes from forbidden to allowed dipole transitions, in relation to changes in localized strain imposed by the substitution of smaller $\mathrm{Y}$ for $\mathrm{Ga}$ atoms into a $\mathrm{CuYO}_{2}$ host lattice. In our case, this is evident from the substitution of the larger $\mathrm{Ga}$ atoms in to the $\mathrm{CuFeO}_{2}$ host.

The principal differences between the transmittance spectra of $\mathrm{CuFe}_{1-\mathrm{x}} \mathrm{Ga}_{\mathrm{x}} \mathrm{O}_{2}$ and that of the pure $\mathrm{CuFeO}_{2}$ samples relate to the accessibility of the direct the $\mathrm{L}$ and $\Gamma$ point transitions located at 1.6 and $2.4 \mathrm{eV}$ respectively. This can be viewed most effectively in Figure 6 which shows the comparative optical densities of the samples, where for sample $\mathrm{C}$ one can observe the increased gradient for the absorption edge located at $2.3 \mathrm{eV}$. The results presented here could be indicating an increase of optical cross-section for these two transition channels over a hybridized band-gap of the alloyed material. The step-like activations of indirect absorption edges observed in sample $\mathrm{C}$ also indicate the increased accessibility of transition channels throughout the spectra in comparison to the pure $\mathrm{CuFeO}_{2}$ material. It is also probable that the spectra represent a hybridization of transition channels between $\mathrm{CuFeO}_{2}$ and the substituted $\mathrm{CuGaO}_{2}$ layers; as the results from the Raman spectra and XRD suggest a significant degree of hybridization of the thin film properties between host and substituted layers. However, a clear differentiation between activated transition channels via symmetry breaking and hybridized bandstructures cannot be made from these results alone. The calculated direct band gaps over the $\mathrm{L}$ and $\Gamma$ points for $\mathrm{CuGaO}_{2}$ are $1.81 \mathrm{eV}$ and $2.4 \mathrm{eV}$ according to Haycock et al [32], and $1.61 \mathrm{eV}$ for the $\Gamma$ point according to Nie et al [33], so an upward shift in absorption edge should also be expected due to hybridization within the alloy, and this is what is observed for the fundamental direct gap absorption edges of the sample.

The results gained from reflectance again show a high dependence on an absorption edge located at 1.2 $\mathrm{eV}$, again providing a similar discrepancy to that described above for the $\mathrm{CuFeO}_{2}$ samples. The fact that the reflectance results gained for the $\mathrm{CuFe}_{1-\mathrm{x}} \mathrm{Ga}_{\mathrm{x}} \mathrm{O}_{2}$ are similar to the $\mathrm{CuFeO}_{2}$ films can be accounted 
for by the capping layer $(\sim 10 \mathrm{~nm})$ of host material applied to the $\mathrm{CuFe}_{1-\mathrm{x}} \mathrm{Ga}_{\mathrm{x}} \mathrm{O}_{2}$ film during growth, assuming a higher proportion of the reflectance spectra emanates from the first few layers of the sample.

\section{Discussion \& Conclusions}

The optical properties of three thin film samples of $\mathrm{CuFeO}_{2}$ and $\mathrm{CuFe}_{1-\mathrm{x}} \mathrm{Ga}_{\mathrm{x}} \mathrm{O}_{2}$ were investigated. XRD and Raman results demonstrated the stoichiometry and high quality of the samples. All samples displayed strong peak Raman shifts located at 350,511 and $689 \mathrm{~cm}^{-1}$, attributed to the octahedral c-axis $\mathrm{E}_{\mathrm{g}}$ vibrational modes, non-zero wave vector phonons, and c-axis A1g vibrational modes respectively; all of which corresponded to characteristic delafossite crystallization within the samples. These peaks were observed to uniformly shift in response to $\mathrm{Ga}$ substitution, indicating a homogeneous hybridization between layers throughout the thin film with respect to phonon channels within the crystal. The Raman shift located at $511 \mathrm{~cm}^{-1}$, showed an increase in allowed optical phonon channels within the material in response to Ga substitution which are forbidden by selection rules for ideally symmetric $\mathrm{CuFeO}_{2}$.

Analysis of Tauc-gaps for the $\mathrm{CuFeO}_{2}$ thin films found agreement with previous reports, with predominant absorption edges measured at $1.1 \mathrm{eV}, 1.4 \mathrm{eV}$ and $2.1 \mathrm{eV}$ from transmittance spectra. The sample of $\mathrm{CuFe}_{1-\mathrm{x}} \mathrm{Ga}_{\mathrm{x}} \mathrm{O}_{2}$ showed a measurable shift $1.5 \mathrm{eV}$ and a strong absorption edge at $2.3 \mathrm{eV}$.

For the composite $\mathrm{CuFe}_{1-\mathrm{x}} \mathrm{Ga}_{\mathrm{x}} \mathrm{O}_{2}$ thin film, changes in characteristic optical absorption edges were observed from Vis-NIR transmittance spectra. Moreover, the overall optical density in the region 1.753.9eV followed a steeper gradient for the $\mathrm{CuFe}_{1-\mathrm{x}} \mathrm{Ga}_{\mathrm{x}} \mathrm{O}_{2}$ thin film above its measured absorption edge at $2.3 \mathrm{eV}$. However, a direct comparison between thin films of near equal thicknesses is yet to be made to show this effect more concretely. The absorption edges observed were attributed to hybridized band 
gaps within the $\mathrm{CuFe}_{1-\mathrm{x}} \mathrm{Ga}_{\mathrm{x}} \mathrm{O}_{2}$ material in conjunction with an increased accessibility of direct band to band transitions over the $\mathrm{L}$ and $\Gamma$ symmetry points within the material. This effect has been linked to crystal symmetry breaking for both host lattice and substituted complexes which leads to the lifting of Laporte' selections rules as described in $[20,32]$. Thus, this $\mathrm{CuFe}_{1-\mathrm{x}} \mathrm{Ga}_{\mathrm{x}} \mathrm{O}_{2}$ epitaxial thin film material could possess some favorable attributes for the purpose of solar driven photo-catalytic electrode applications. This finding has shown that b-site alloying provides scope for further investigations aimed towards engineering a delafossite material with a strong direct absorption edge in the region of peak solar irradiance, which can be changed by varying the alloy constituents and concentrations. Although the results obtained from reflectance measurements are comparable with the fundamental band gaps obtained from transmittance at $1.2-1.4 \mathrm{eV}$, they also suggest that near surface transitions vary with respect to absorption channels through the bulk of the material and that intra-gap surface states may have a contribution to the available direct absorption channels close to the surface. Given that photocatalysis is a surface located event this may have influence on the properties of the material in terms of photochemical water-splitting reactions amongst other possible applications.

Further investigations of the photo-current generation, carrier mobilities and photo-catalytic reactions on the sample surfaces will help determine the impact of the substituted layers and surface absorption channels on the generation of the electron-hole pairs required for photo-catalytic processes within the materials investigated.

\section{Acknowledgments}

This work at PUC was supported by FONDECyT 1130372 and Proyecto Anillo ACT1409. This work at WVU was supported in part by the WV Higher Education Policy Commission (grant HEPC.dsr.12.29) and by FAME, one of six centers of STARnet, a Semiconductor Research Corporation program sponsored by MARCO and DARPA (contract \# 2013-MA-2382). 


\section{References}

[1] A. Angelis-Dimakisa, M. Biberacherb, J. Dominguez, G. Fioresed, S. Gadochab, E. Gnansounouf, G. Guarisod, A. Kartalidisa, L. Panichellif, I. Pinedoc, M. Robbag, Renew Sust Energ Rev 15 (2) (2011) 1182

[2] John Andrews, Bahman Shabani, Int J Hydrogen Energ 37 (2012) 1184

[3] M.S. Dresselhaus, I.L. Thomas, Nature 414 (2001) 332

[4] S.J. Lao, H.Y. Qin, L.Q. Ye, B.H. Liu, Z.P. Li, J. Power Sources 195 (13) (2010) 4135

[5] A. Fujishima, K. Honda, Nature 238 (5385) (1972) 37

[6] A. P. Finlayson, V. N. Tsaneva1, L. Lyons, M. Clark, and B. A. Glowacki, Phys Status Solide A 203(2) (2006) 327-335

[7] Michael Gratzel, Nature 414 (2001) 338

[8] K. Maeda, J Photoch Photobio C: Photoch. Rev 12 (4) (2011) 237

[9] W. Shockley and H. J. Quiesser, J Appl Phys 32(3), 510 (1961)

[10] M. N. Huda, Y. Yan, A. Walsh, S-H Wei, M M Al-Jassim, Phys Rev B 80 (2009) 035205

[11] V.R. Galakhov, A. I. Poteryaev, E. Z. Kurmaev, V. I. Anisimov, St. Bartkowski, M. Neumann, Z. W. Lu, B. M. Klein, and Tong-Rong Zhao, Phys Rev B 56 (1997) 4584

[12] H. Hiraga, T. Makino, T. Fukumura, H. Weng, and M. Kawasaki, Phys Rev B 84 (2011) 041411(R)

[13] Toyanath Joshi, Tess R. Senty, Robbyn Trappen, Jinling Zhou, Song Chen, Piero Ferrari, Pavel Borisov, Xueyan Song, Mikel B. Holcomb, Alan D. Bristow, Alejandro L. Cabrera, David Lederman, J Appl Phys 117 (2015) 013908

[14] F.A. Benko F.P. Koffyberg, J Phys Chem Solids 48 (1987) 431

[15] Z. Deng, X. Fang, S. Wu, W. Dong, J. Shao, S. Wang, M. Lei , J Sol-Gel Sci Techn 71 (2014) 297-302 
[16] G. Riveros , C. Garín, D. Ramírez, E.A. Dalchiele, R.E. Marotti, C.J. Pereyra, E. Spera, H. Gómez, P. Grez, F. Martín, J.R. Ramos-Barrado. Electrochim Acta 164 (2015) 297-306

[17] M. Lalanne, A. Barnabe, F. Mathieu, and Ph. Tailhades, Inorg Chem 48 (2009), 6065- 6071

[18] S.Y. Zheng, G.S. Jiang, J.R. Su, C.F. Zhu, Mater Lett 60 (2006) 3871-3873

[19] S.H. Lim, Suma Desu, A.C. Rastogi , J Phys Chem Solids 69 (2008) 2047-2056

[20] J. W. Lekse, M. K. Underwood, J. P. Lewis, and C. Matranga, J Phys Chem.C 116 (2012) $1865-1872$

[21] M. Lee, D. Kim, Y. T. Yoon, Y. I. Kim, B Kor Chem Soc 35, issue 11(2014) 3261-3266.

[22] S. Rojas, T. Joshi, R.A.Wheatley, M. Sarabia, P. Borisov, D. Lederman, A.L. Cabrera, Surf Sci 648 (2016) 23-28

[23] N. P. Salke, K. Kamali, T.R. Ravindran, G. Balakrishnan, R. Rao, Vib Spectrosc 81 (2015) 112118

[24] J. Pellicer-Porres, A. Segura, C. Ferrer-Roca, D.Martınez-Garcıa, J.A. Sans, E. Martınez, J.P. Itie', A. Polian, F. Baudelet, A. Munoz, P. Rodriguez-Hernandez, P. Munsch, Phys Rev B 69 (2004) 024109

[25] O. Aktas, K. D. Truong, T. Otani, G. Balakrishnan, M. J. Clouter, T. Kimura and G. Quirion, J Phys-Condens Mat 24 (2012) 036003

[26] J. Tauc, Mater Res Bull, 3 (1968) 37-46

[27] J.I. Pankove, Optical Processes in Semiconductors (Prentice Hall, 1971)

[28] Shimadzu, Article, Spectrophotometric Analysis, No.A428 (online)

[29] J. Tauc, R. Grigorovici, and A. Vancu, Phys. Status Solidi, 15627 (1966).

[30] R Lopez andR Gomez, J. Sol-Gel. Sci. Technol, 61:1-7 (2012).

[31] K. P. Ong, K. Bai , P. Blaha, and P. Wu, Chem Mater 2007, 19 (3), 634-640

[32] B. J. Haycock, M. K. Rice and J. P. Lewis, Comp. Mat. Sci. 86 (2014) 155-164 
[33] X. Nie, S. Wei, and S. B. Zhang, Phys. Rev. Lett, Vol 88. No 6, 2002

[34] M. Fox, The optical properties of solids, Oxford University Press, 2006. 


\section{LIST OF FIGURES}

Figure 1. Schematic diagram of the optical apparatus: A $100 \mathrm{~W}$ tungsten halogen lamp provides the broadband light source. PD-2 is the photodetector used to collect transmitted light recorded at normal incidence $\left(\theta=0^{\circ}\right)$, PD-1 is the photodetector used to collect reflected light (angle of reflectance $\left.\theta<10^{\circ}\right)$; transmittance is. The beam is chopped $(730 \mathrm{~Hz})$

Figure 2. XRD diffraction spectra for both $\mathrm{CuFeO}_{2}$ samples: $21 \mathrm{~nm}$ thick film is shown with a blue line; $75 \mathrm{~nm}$ thick film is shown with a red line.

Figure 3. Raman spectra of the samples: black line corresponds to the spectrum of sample A (21 nm $\left.\mathrm{CuFeO}_{2}\right)$, green line corresponds to the spectrum of sample $\mathrm{B}(75 \mathrm{~nm} \mathrm{CuFeO})$ and blue line corresponds to the spectrum to sample $\mathrm{C}\left(37 \mathrm{~nm} \mathrm{CuFe} \mathrm{ndx}_{-\mathrm{x}} \mathrm{Ga}_{\mathrm{x}} \mathrm{O}_{2}\right)$. Raman peaks labeled with (*) correspond to the $\mathrm{Al}_{2} \mathrm{O}_{3}$ substrate.

Figure 4. (a) Plot of the transmittance spectra as a function of photon energy for all samples: blue line corresponds to the spectrum of sample A, red line corresponds to the spectrum of sample and black line corresponds to the spectrum to sample C ,

(b) Plot of the reflectance spectra as a function of photon energy for sample $\mathrm{A}\left(\mathrm{CuFeO}_{2}\right)$ and sample $\mathrm{C}\left(\mathrm{CuFe}_{1-\mathrm{x}} \mathrm{Ga}_{\mathrm{x}} \mathrm{O}_{2}\right)$.

Figure 5 (a) Tauc-plot from transmittance data ( $n=1 / 2$ in Eq. (1)): (a) for sample A

(b) for sample B (c) for sample C

Figure 6 Plot of the relative optical densities for each sample (sample A, B and C) for comparison.

Figure 7 Tauc-plot for the K-M function of reflectance $(F(R)$ replaced $\alpha$ in Eq. (1) and using $n=1 / 2$ ). (a) for sample A (b) for sample C. 


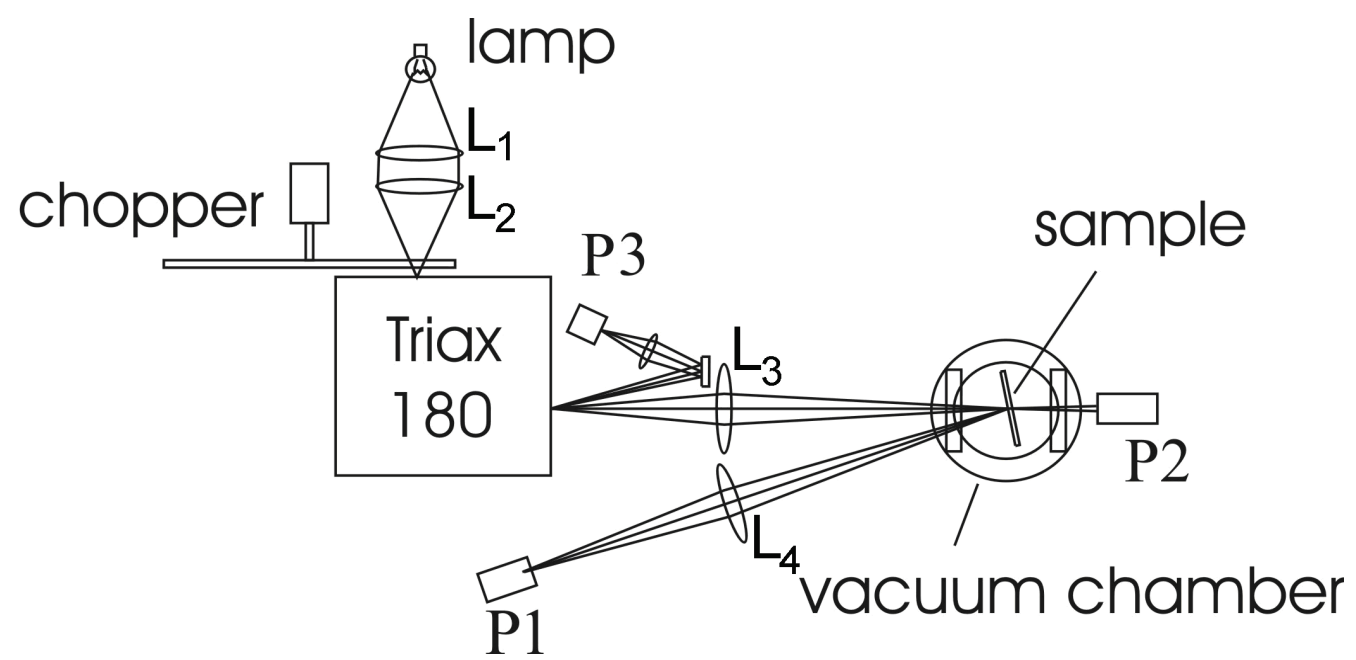

FIG. 1 


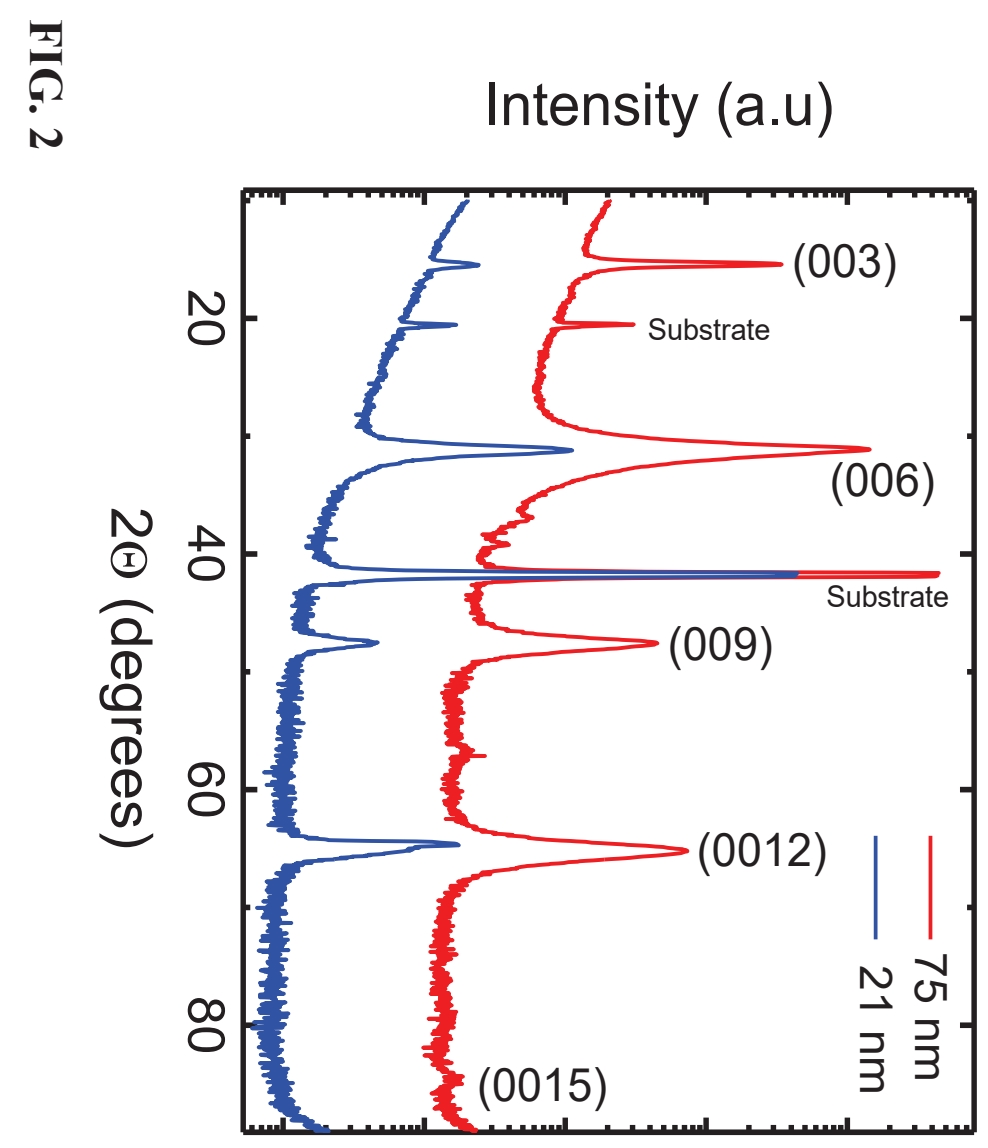




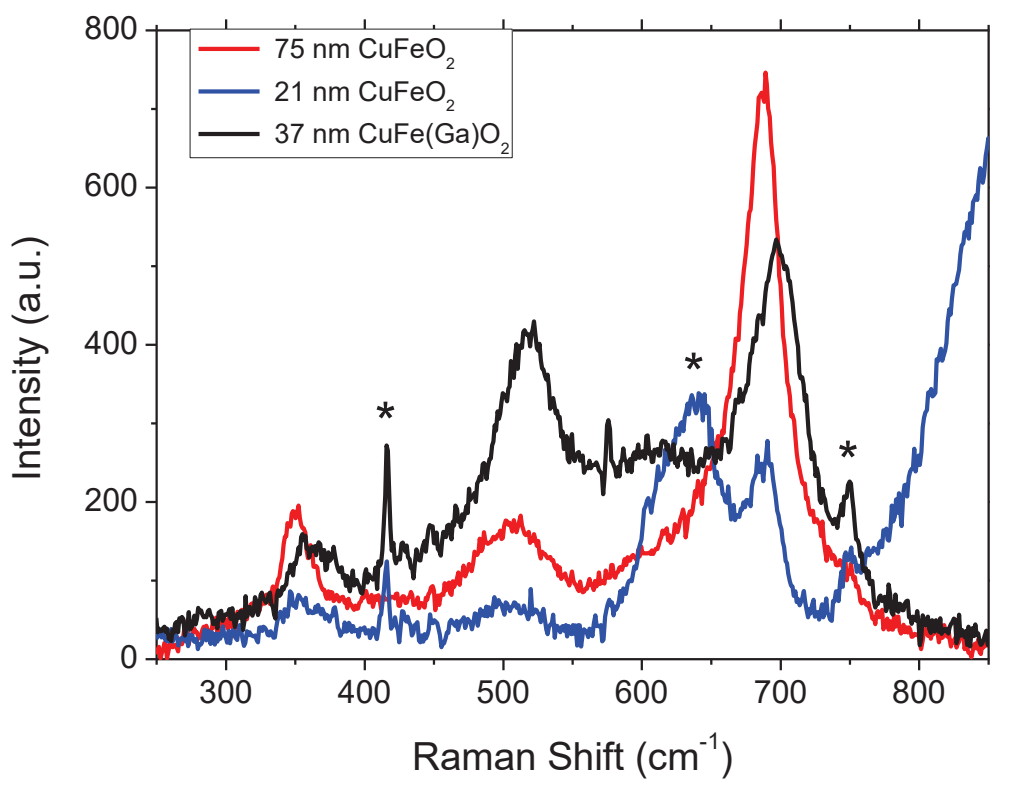

FIG. 3 

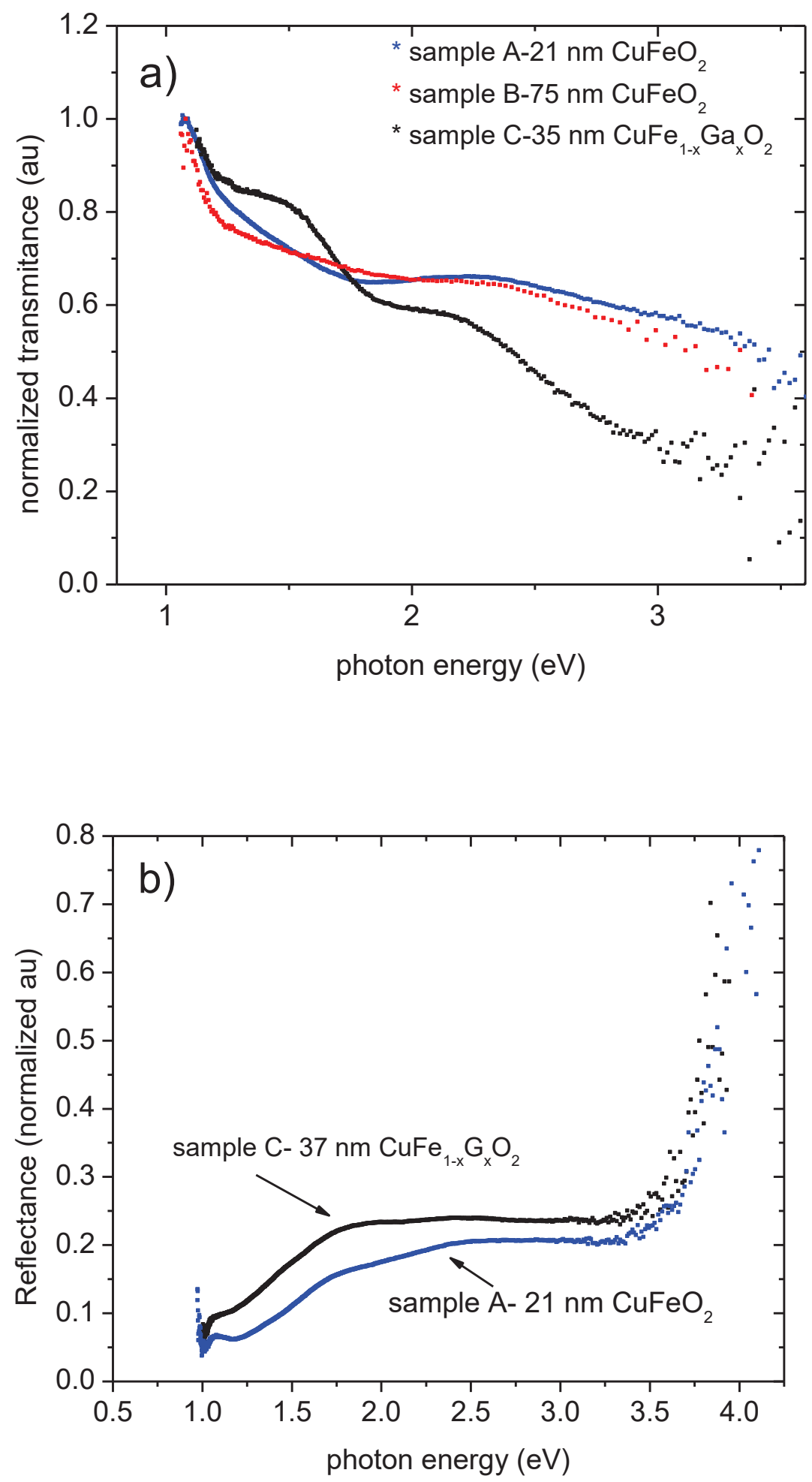

FIG. 4 

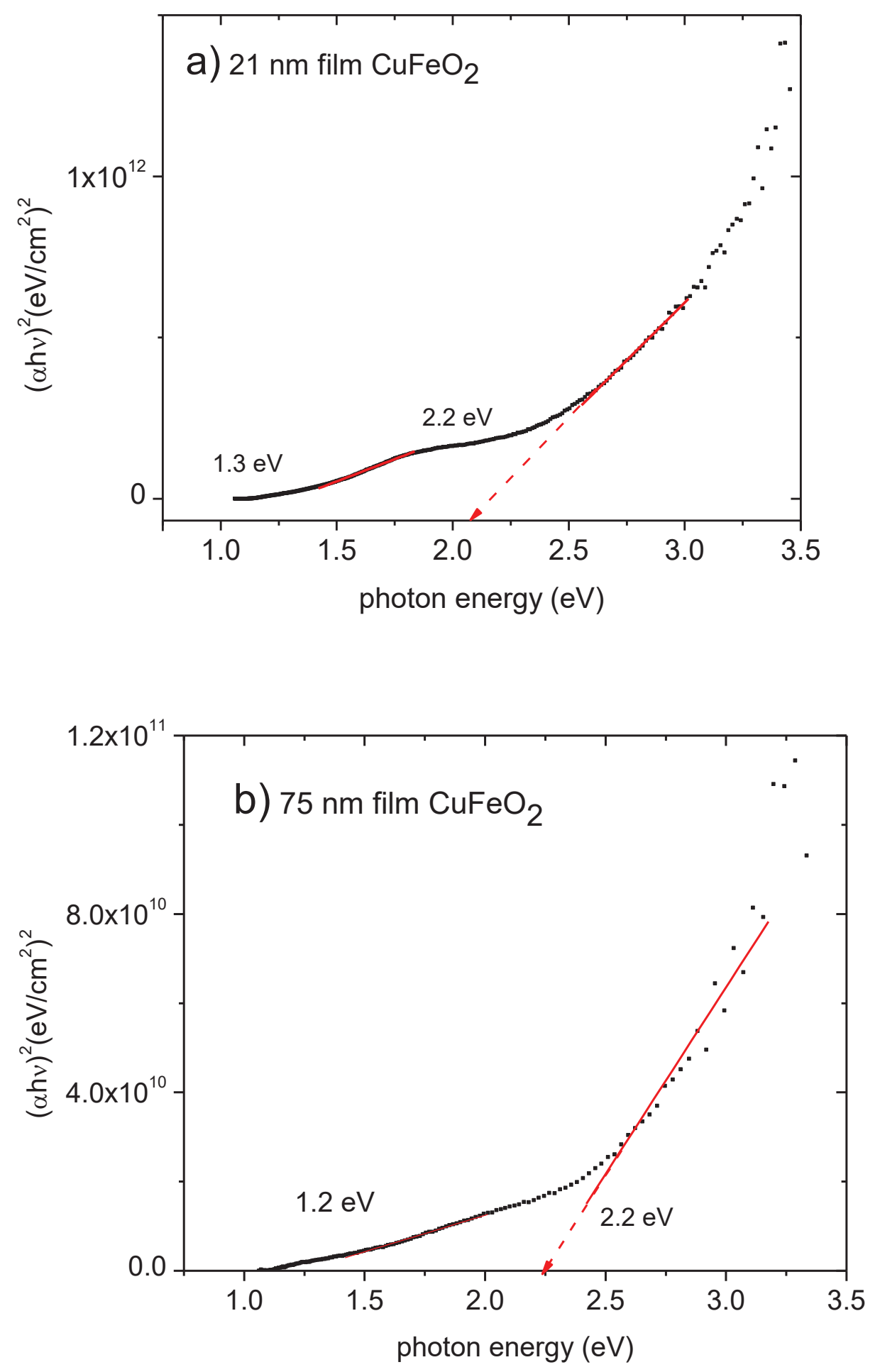


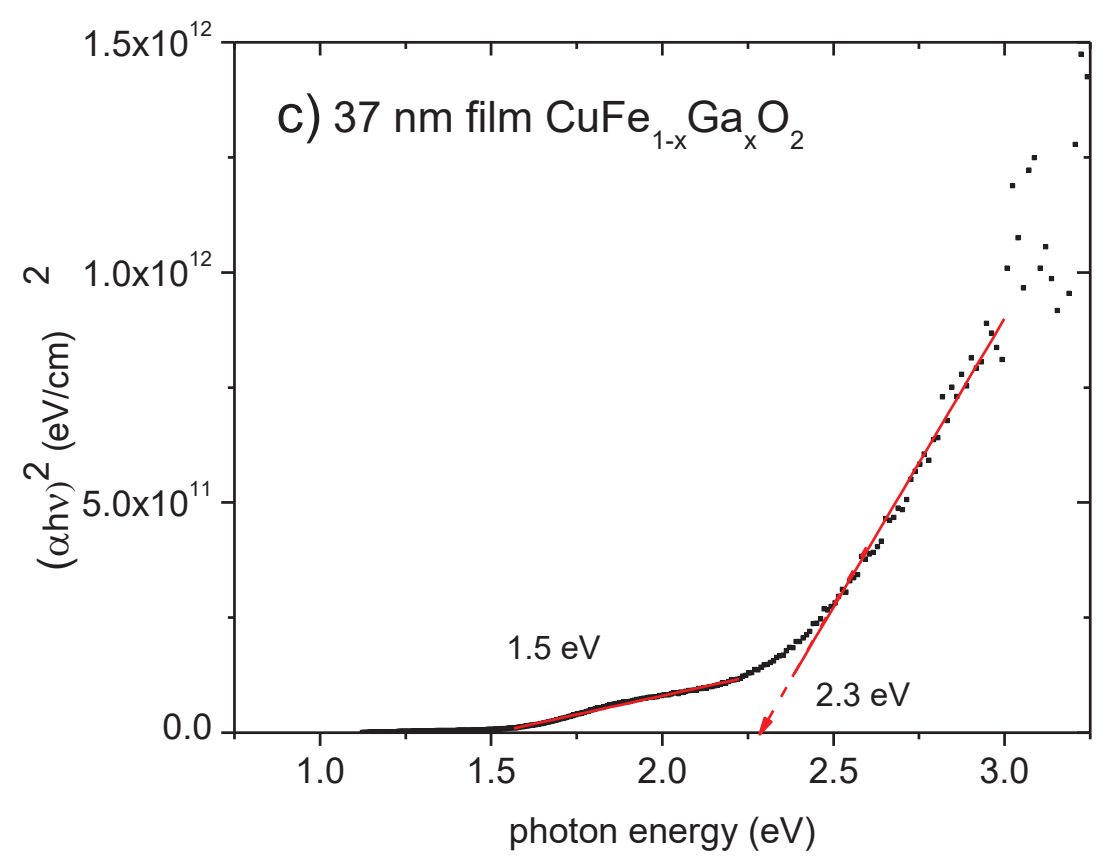

FIG.5 


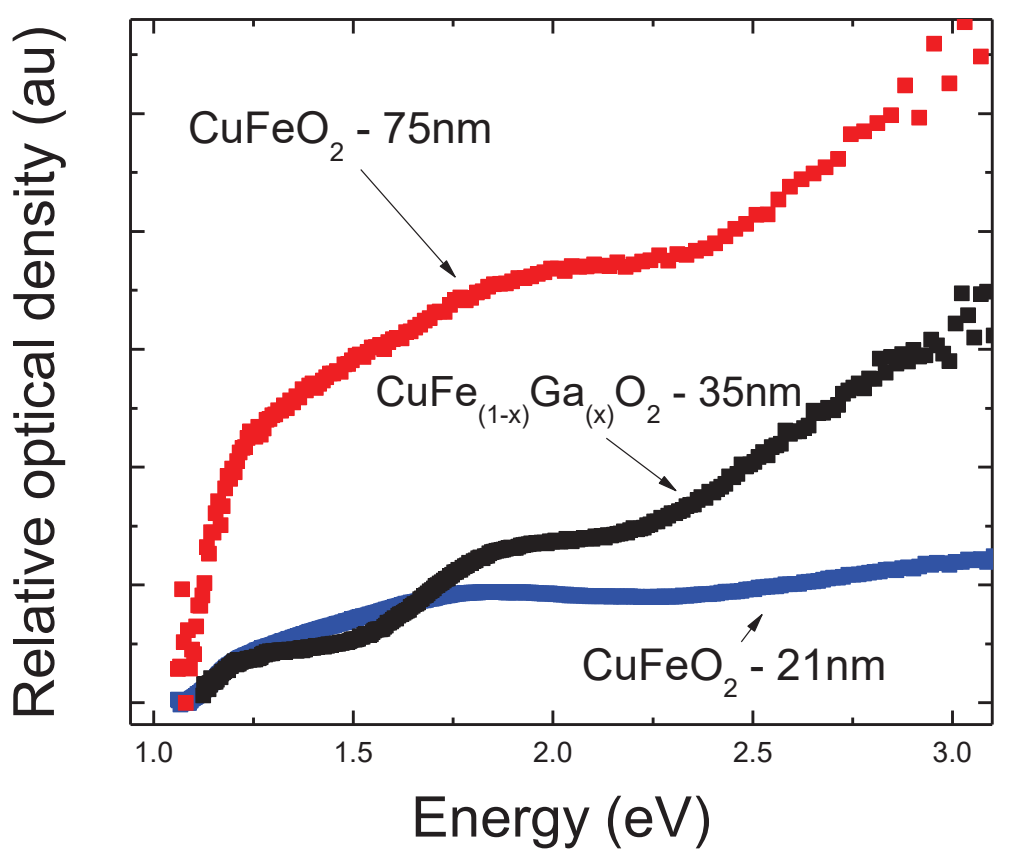

FIG.6 

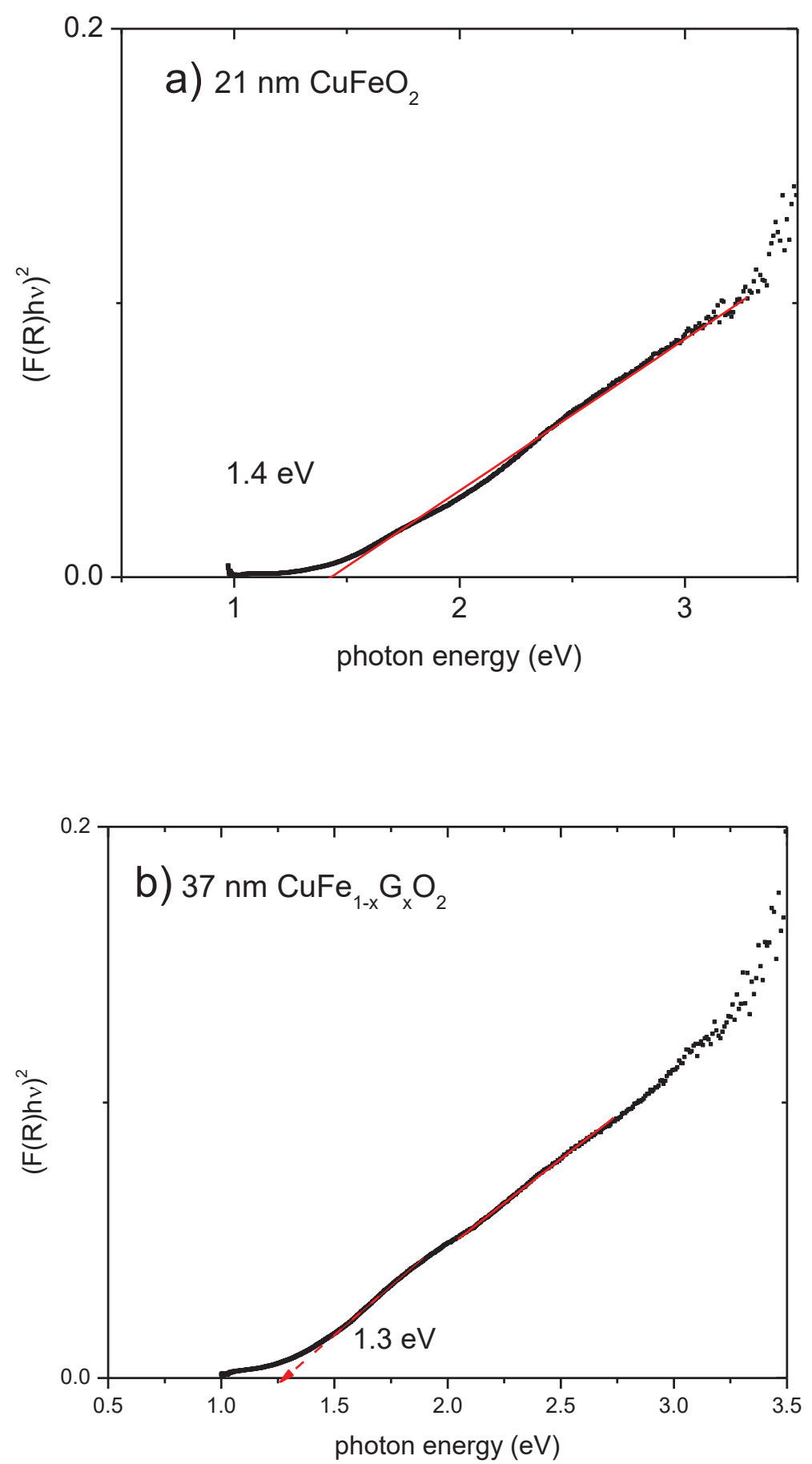

FIG.7 